\title{
Parallel Profiling of the Transcriptome, Cistrome, and Epigenome in the Cellular Response to lonizing Radiation
}

\author{
Sharon Rashi-Elkeles, ${ }^{1 \star}$ Hans-Jörg Warnatz, ${ }^{2 \star}$ Ran Elkon,, ${ }^{1 \star}$ Ana Kupershtein, ${ }^{1}$ \\ Yuliya Chobod, ${ }^{1}$ Arnon Paz, ${ }^{1}$ Vyacheslav Amstislavskiy, ${ }^{2}$ Marc Sultan, ${ }^{2}$ Hershel Safer, ${ }^{3}$ \\ Wilfried Nietfeld, ${ }^{2}$ Hans Lehrach, ${ }^{2}$ Ron Shamir, ${ }^{3}$ Marie-Laure Yaspo, ${ }^{2}$ Yosef Shiloh ${ }^{1 \neq}$
}

\begin{abstract}
The DNA damage response (DDR) is a vast signaling network that is robustly activated by DNA doublestrand breaks, the critical lesion induced by ionizing radiation (IR). Although much of this response operates at the protein level, a critical component of the network sustains many DDR branches by modulating the cellular transcriptome. Using deep sequencing, we delineated three layers in the transcriptional response to IR in human breast cancer cells: changes in the expression of genes encoding proteins or long noncoding RNAs, alterations in genomic binding by key transcription factors, and dynamics of epigenetic markers of active promoters and enhancers. We identified protein-coding and previously unidentified noncoding genes that were responsive to IR, and demonstrated that IR-induced transcriptional dynamics was mediated largely by the transcription factors p53 and nuclear factor $\kappa B$ (NF-кB) and was primarily dependent on the kinase ataxia-telangiectasia mutated (ATM). The resultant data set provides a rich resource for understanding a basic, underlying component of a critical cellular stress response.
\end{abstract}

\section{INTRODUCTION}

The DNA molecule is highly susceptible to the action of endogenous and exogenous DNA damaging agents (1). Defending against this continuous threat to genomic stability is critical for cellular homeostasis, for proper organism development, and for prevention of undue cell death, cancer, and premature aging. The DNA damage response (DDR) is a signaling network that activates crucial DNA repair mechanisms and an elaborate series of events that swiftly modulate many physiological processes $(2,3)$. Its importance is highlighted by mutations that lead to serious genomic instability syndromes, usually characterized by degeneration of specific tissues, cancer predisposition, and sensitivity to DNA damaging agents $(4,5)$. A broader effect on public health is conferred by heterozygosity for mutations that inactivate certain DDR players, such as the breast cancer-associated proteins BRCA1 and BRCA2, the transcription factor $\mathrm{p} 53$, and mismatch repair proteins. Such genotypes result in predisposition to specific cancers, emphasizing the intimate link between the formation and progression of cancers and genomic instability [reviewed in (6)]. Furthermore, it is becoming clear that differences in maintaining genomic stability are reflected in the variations observed in aging and associated diseases in the general population (7). Finally, because first-line treatment modalities for many cancer types are based on radiation and DNA damaging chemicals, these modalities can be modified and refined only by understanding the DDR $(8,9)$. An important model lesion in the study of the DDR network is the DNA double-strand break (DSB) - an extremely harmful DNA lesion that vigorously activates this network $(2,3,10)$. DSBs can be induced by ionizing radiation (IR),

\footnotetext{
${ }^{1}$ The David and Inez Myers Laboratory for Cancer Research, Department of Human Molecular Genetics and Biochemistry, Sackler School of Medicine, Tel Aviv University, Tel Aviv 69978, Israel. '2Department of Vertebrate Genomics, Max Planck Institute for Molecular Genetics, Ihnestrasse 63-73, 14195 Berlin, Germany. ${ }^{3}$ Blavatnik School of Computer Science, Tel Aviv University, Tel Aviv 69978, Israel.

*These authors contributed equally to this work.

†Present address: Division of Gene Regulation, The Netherlands Cancer Institute, 121 Plesmanlaan, 1066 CX Amsterdam, The Netherlands. ‡Corresponding author. E-mail: yossih@post.tau.ac.il
}

radiomimetic chemicals, or endogenous reactive oxygen species. They also accompany physiological genomic transactions such as meiotic recombination (11) and the rearrangement of antigen receptor genes in the adaptive immune system (12). Within seconds of DSB formation, the DSB response network activates repair mechanisms and specific cell cycle checkpoints, moderates protein synthesis, activity, and turnover, and regulates many other aspects of cellular metabolism. The chief transducer of the DSB response is the protein kinase ATM (ataxia-telangiectasia mutated). This homeostatic, versatile protein kinase is strongly activated after DSB formation and mobilizes the cellular response to the lesion by phosphorylating key players in its numerous branches [reviewed by (13)]. The DDR is a multilayered process that impacts the epigenome, transcriptome, RNA processing and translation, and protein dynamics. It induces posttranslational modifications (PTMs) in numerous proteins that affect their function, stability, subcellular localization, and interactions (14). Despite this marked complexity, the process is highly structured in time and space and meticulously controlled. An overview of the DDR requires a systems biology approach (15-18). Although the dynamics of protein PTMs and their functional consequences are relatively fast and readily discernible, a deep, vast layer of the DDR operates at the level of gene expression. It complements the dynamics of protein PTMs by maintaining cellular homeostasis during DNA repair, particularly if the cell cycle is arrested, or during programmed cell death if that route is initiated (19). Previous studies of gene expression after DNA damage or physiological DNA breaks relied mainly on gene expression microarrays. The powerful successor of this technology, RNA deep sequencing (RNA-seq), offers a considerably more profound and less biased view of the cellular transcriptome. Gene expression can be surveyed at an unprecedented depth because of the precision and high resolution of this technology and its ability to capture weakly expressed RNAs as well as RNA species that are usually not represented in common microarrays (20). A similar quantum leap was made in mapping the genomic binding of proteins, such as transcription factors, when deep sequencing was combined with chromatin immunoprecipitation (ChIP-seq) $(21,22)$. Here, we integrated RNA-seq and ChIP-seq analyses to explore the IRinduced modulation of the cellular transcriptome and cistrome of key 
transcriptional regulators, and correlated these alterations with those of epigenetic markers of active enhancers and promoters. The results delineated this arm of the DDR and its regulators in great detail and substantiate its importance in what seems to be one of the most extensive cellular responses to a stimulus.

\section{RESULTS}

\section{Transcriptome dynamics after $\mathbf{X}$-irradiation}

To obtain a comprehensive view of the modulation of the cellular transcriptome in response to IR, we analyzed the IR-induced response in the CAL51 breast cancer cell line, established from pleural effusion of metastatic breast cancer (23). CAL51 cells exhibit morphological and immunohistochemical characteristics of epithelial mammary cells, are tumorigenic in nude mice, and have wild-type p53 and a normal karyotype. We confirmed that CAL51 cells show typical DDRs to X-irradiation: their cellular sensitivity to IR was markedly enhanced upon chemical inhibition of ATM (fig. S1A), and they activate DNA damage-induced cell cycle checkpoints in an ATMdependent manner (fig. S1B). X-irradiation induced in these cells ATM autophosphorylation and phosphorylation of several ATM substrates, as well as increased abundance of $\mathrm{p} 53$ and $\mathrm{p} 21$ (encoded by $C D K N 1 A$, which is a p53 target induced by DNA damage) (fig. S1C). To determine informative time points for transcriptome profiling after IR treatment, we initially used expression microarrays to characterize this response in CAL51 cells at eight time points during the first 24 hours after irradiation with $5 \mathrm{~Gy}$ of $\mathrm{x}$-rays. We identified two waves of gene induction after irradiation: genes peaking at
4 hours were labeled early responders, and genes peaking at 8 hours were labeled late responders (fig. S1D and table S1). These time points were then selected for RNA-seq experiments. Having found early on that transcriptome dynamics were very sensitive to minor stresses (such as removing cell culture flasks from the incubator and handling them during treatment and analyses), we used time-matched unirradiated cultures as controls for each time point, in addition to the zero-time cultures. These control cultures were handled identically to the experimental cultures, except that they were not irradiated.

The number of RNA-seq reads that uniquely mapped to the human genome ranged from 45 to 68 million per sample (table S2). Overall, we detected the expression of 18,054 genes, of which 11,113 were protein-coding. To examine this data set for genes that responded to radiation treatment (Fig. 1A), we set an adjusted fold change threshold. Because measurement variability is greater among lowly expressed genes, the adjusted threshold is more stringent for these genes compared with the highly expressed ones (Fig. 1B and fig. S1E). We detected 299 and 382 genes that had increased expression at 4 and 8 hours, respectively (table $\mathrm{S} 3 \mathrm{~A}$ ), with substantial overlap between the two groups (Fig. 1C). Notably, the number of repressed genes detected at 4 and 8 hours [74 and 32, respectively (table S3B)] was about fivefold less than the number of induced genes. According to Gene Ontology (GO) enrichment analysis (table S4), the most highly enriched population was genes that encoded apoptotic proteins (55 genes) including $B A X, B B C 3, F A S$, and many members of the tumor necrosis factor (TNF) receptor family. Additional overrepresented categories were "regulation of cell growth" and "response to hypoxia." The set of repressed genes was highly enriched for cell cycle

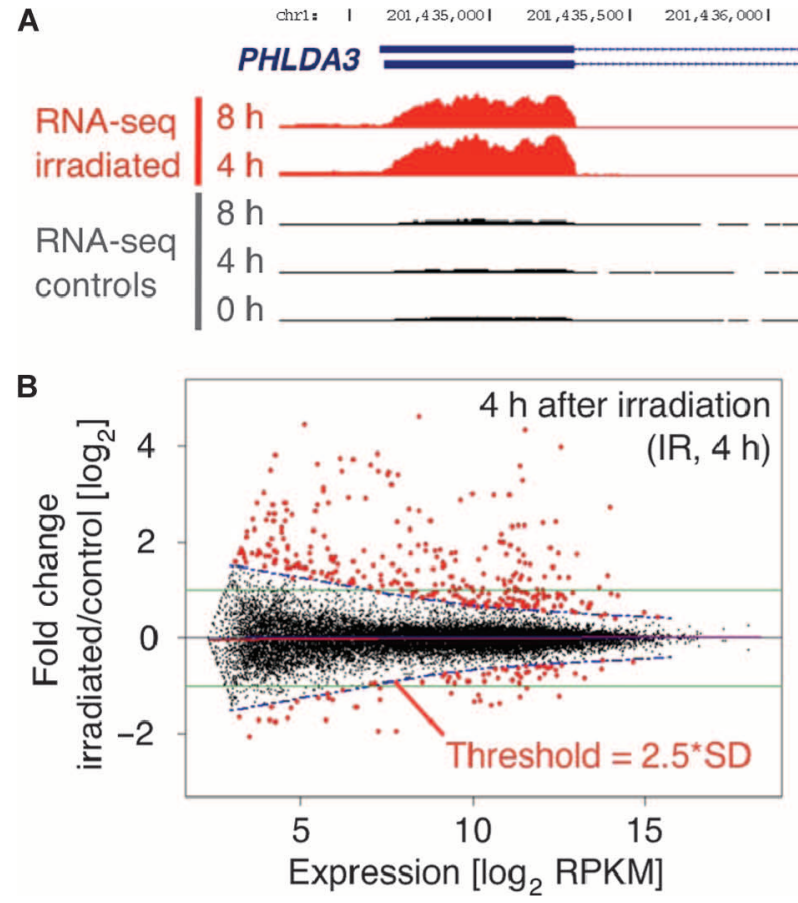

Fig. 1. IR-responsive genes identified using RNA-seq. (A) Example of an IRinduced gene, PHLDA3, detected by RNA-seq at 4 and 8 hours after irradiation of CAL 51 cells with 5 Gy of IR. (B) RNA-seq of gene expression in control and after IR. An adjusted fold change threshold was set to define IR-responsive genes: the SD of fold change (at a $\log _{2}$ scale) was obtained as a function of expression, and responsive genes (red dots) were defined as

those whose fold change was at least 2.5-fold the SD (dashed blue lines). Data are shown for the 4-hour time point. Genes (299 and 74) were defined as IR-induced and IR-repressed genes, respectively. RPKM, reads per kilobase per million reads. (C) Overlap between genes defined as IR-induced or IR-repressed at 4 and 8 hours after irradiation. The list of genes is provided in table S3. All data are representative of two independent experiments. 
genes (34 genes), especially those that encode proteins that function in the $\mathrm{M}$ phase (22 genes).

\section{Control of the transcriptional response to IR by $\mathrm{p53}$, NF-кB, and ATM}

Pathway analysis indicated that the group of IR-induced genes was highly enriched for p53-associated signaling pathways (fig. S2A), suggesting that p53 is the key regulator of the transcriptional response to IR. We examined how much of this response was p53-dependent by decreasing p53 abundance in CAL51 cells using RNA interference (fig. S2B) and reapplying RNA-seq to p53-deficient and control cells 4 and 8 hours after irradiation. Cluster analysis applied to the combined RNA-seq data set identified the major kinetic patterns exhibited by the IR-responsive genes - induced or repressed (Fig. 2 and fig. S2C, respectively, and table S5) - and demonstrated a crucial role of p53 in this response. Knocking down p53 compromised the vast majority of the transcriptional response to IR, largely abolishing both induction and repression of gene expression. Although most of the IR-induced gene clusters showed a p53-dependent response (see clusters 1 to 3 in Fig. 2 and table S5), one relatively small cluster contained genes whose induction in response to IR was not markedly attenuated upon p53 silencing (cluster 4 in Fig. 2 and table S5). This cluster contained several genes that encode key components of the nuclear factor $\kappa \mathrm{B}(\mathrm{NF}-\kappa \mathrm{B})$ pathway [including NF- $\mathrm{KB}$ subunits (NFKB2 and RelB) and major regulators of that pathway (NFKBIA and NFKBIE)] and direct gene targets of NF- $\mathrm{BB}$ (BIRC3, CD83, and TNFAIP3). Activation and stabilization of $\mathrm{p} 53$ after the induction of DSBs are ATM-dependent and are carried out by an ATM-directed network involving at least a dozen direct and indirect

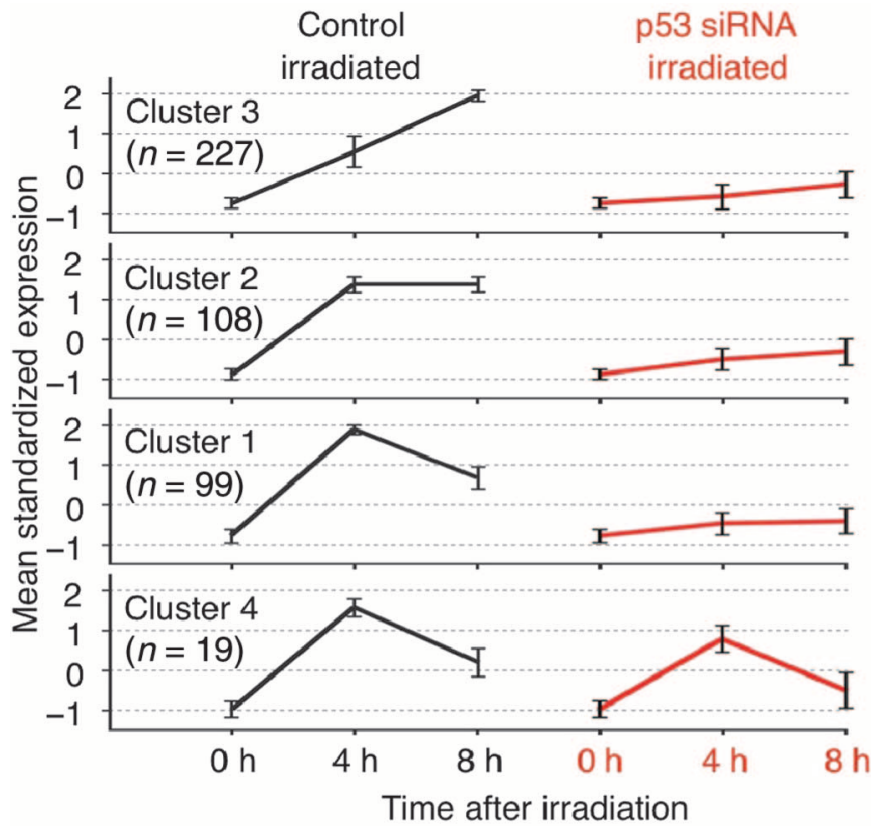

Fig. 2. Effect of p53 depletion on the transcriptional response to IR. Expression of IR-induced genes using RNA-seq in control or p53-deficient CAL51 cells at 0,4 , or 8 hours after irradiation. Genes were subjected to cluster analysis to delineated major kinetic patterns of expression and p53 dependence. Data are the mean expression of the total genes in each cluster $(n) \pm \mathrm{SD}$. Expression of each gene was standardized to mean $=0$ and $\mathrm{SD}=1$ before clustering; the $y$ axis represents standardized values. The list of genes is provided in table S5.
ATM substrates [reviewed in (13)]. To examine the ATM dependence of the IR-induced transcriptome modulations, we applied the ATM inhibitor KU-55933 to CAL51 cells, which were then irradiated along with inhibitorfree and p53-deficient cells, and monitored the transcriptome dynamics using expression microarrays. The effect of ATM inhibition was stronger than that of p53 silencing (Fig. 3A and table S6), indicating the greater control that ATM has over this process. Our experiments identified numerous genes that are induced in response to IR through the ATM-p53 signaling axis. For validation, we selected 13 genes encoding proteins whose role in the DDR had not been characterized in detail. Quantitative real-time polymerase chain reaction (qRT-PCR) analysis validated the ATM- and p53-dependent IR induction of all 13 genes (Fig. 3B). Among them are $A E N$, which encodes a nuclear exonuclease required for p53-dependent apoptosis (24) and was recently linked to $\mathrm{p} 53$-dependent autophagy in response to DNA damage induction (25); $L R D D$, whose protein product interacts with several death domain proteins, such as Fas-associated death domain (FADD) and mitogenactivated protein kinase-activating death domain-containing protein (MADD)

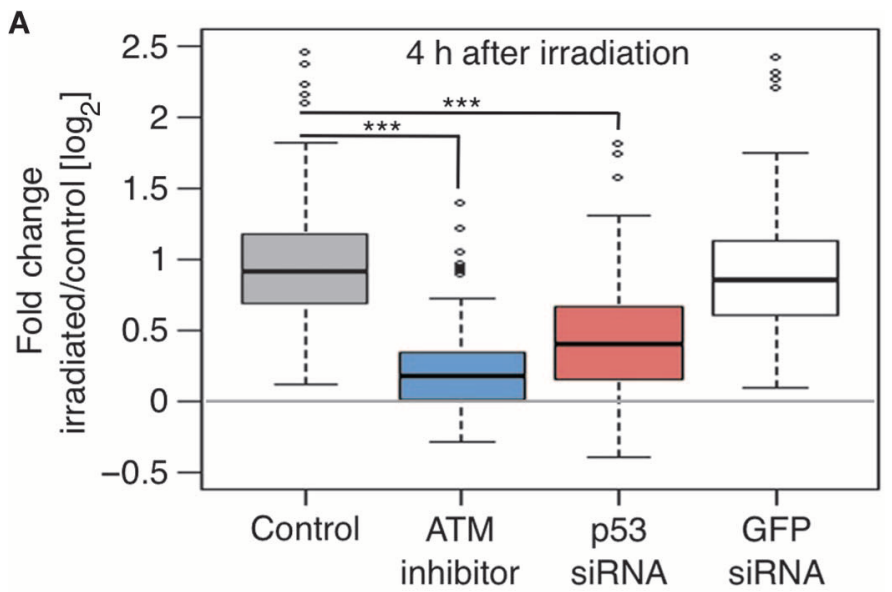

B
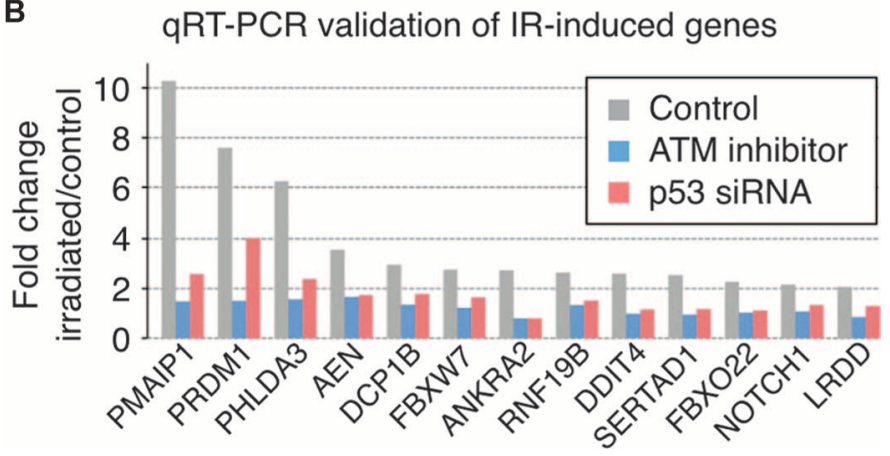

Fig. 3. Effect of ATM inhibition on the IR-induced transcriptional response. (A) Expression microarrays were used to profile the transcriptional response to IR in CAL51 control cells (5 Gy, 4 hours after irradiation), and in CAL51 cells treated with ATM inhibitor, or small interfering RNA (siRNA) against p53 or green fluorescent protein (GFP). One hundred twelve genes were significantly induced by IR in control cells ( $t$ test; $F D R=1 \%$ ). Box plots show fold change distributions in the expression in irradiated versus nonirradiated samples from three independent replicates. ${ }^{* *} P<1.0 \times 10^{-19}(P=1.0 \times$ $10^{-29}$ for the effect of ATM inhibition and $P=7.9 \times 10^{-20}$ for the effect of p53 knockdown, Wilcoxon test). (B) qRT-PCR validation of the ATM- and p53-dependent response for 13 IR-induced genes. 
(26), and thus may function as an adaptor protein in cell death-related signaling processes; $P H L D A 3$, which encodes a repressor of Akt, a major prosurvival kinase (27); the genes encoding the F-box proteins FBXO22 and FBXW7, subunits of SCF ubiquitin ligase complexes; $R N F 19 B$, encoding an E3 ubiquitin ligase; $D C P 1 B$, encoding an RNA decapping enzyme; and DDIT4, encoding an inhibitor of signaling associated with mammalian target of rapamycin (mTOR).

\section{IR-induced expression of long noncoding RNAs}

An important, recently identified class of transcripts is long noncoding RNAs (lncRNAs). IncRNAs contain at least 200 nucleotides and, similar to mRNAs, contain a $5^{\prime}$ cap and a $3^{\prime}$ polyadenylate $[\operatorname{poly}(\mathrm{A})]$ tail. Thousands of lncRNA genes were recently reported in humans and mice. Evidence suggests that lncRNAs play substantial regulatory roles in diverse biological processes, such as transcriptional regulation, genetic dosage compensation, cell cycle regulation, and development [for a recent review, see (28)]. Certain IncRNAs function in recruitment of protein complexes to chromatin, or to act as scaffolds or decoys. However, the mode of action of most lncRNAs remains to be disclosed (28-30). Our RNA-seq data set detected the expression of 379 transcripts annotated as lncRNAs. Eight lncRNAs were significantly induced by IR (Fig. 4A and table S7).

Remarkably, induction of all eight lncRNAs by IR was markedly attenuated in p53-deficient cells (table S7). We validated the p53-dependent induction of three lncRNAs using qRT-PCR (Fig. 4B). Notably, the transcription of the lncRNA RP3-510D11.2 was initiated from the same promoter that regulates the production of the primary transcript of the microRNA miR-34aanother IR-induced transcript. This promoter is thus bidirectional and encodes two different types of noncoding RNAs in opposite directions (fig. $\mathrm{S} 3 \mathrm{~A}$ ). LINC00086 is another lncRNA that is induced by IR in a p53-dependent manner (Fig. 4B). Also notably, this lncRNA is strongly induced by Nutlin-3a, a potent inhibitor of mouse double minute 2 homolog (MDM2), a ubiquitin
E3 ligase that targets p53 (31). Another IR-induced lncRNA that we validated has not yet been annotated. This transcript is about $2 \mathrm{~kb}$ long and is encoded by a locus on chromosome $9 \mathrm{q} 34$ within a genomic region that is highly enriched for active regulatory elements, according to the ENCODE project (fig. S3B). We presume that this noncoding transcript belongs to the family of enhancer RNAs (eRNAs) (32). Recently, a p53-regulated eRNA was demonstrated to be required for the activation of downstream p 53 target genes (33).

In addition, although standard RNA-seq does not measure the expression of mature microRNAs (miRs) because of their small size, we did detect p53-dependent induction of the pre-mRNA of miR-34a (fig. $\mathrm{S} 3 \mathrm{~A}$ ). miR-34a was the first miR identified as a p53 target and was reported to enhance p53-mediated induction of apoptosis $(34,35)$.

\section{Identification of direct p53 targets and determinants of p53-binding outcomes}

The predominance of p53 in IR-induced transcriptome dynamics could be manifested through both direct and secondary p53 target genes. We applied ChIP-seq analysis to identify direct p53 target genes in this extensive p53dependent network (Fig. 5A), and identified 1830 IR-induced p53-binding events across the genome [false discovery rate $(\mathrm{FDR})=5 \%$ ]. Linking a 53 binding site with its putative target gene [on the condition that the site was located between 15 kilobase pairs (kbp) upstream of the gene's transcription start site (TSS) and the gene's transcription end site (TES)] resulted in 1115 p53-binding sites associated with 982 putative target genes (table S8A). De novo motif analysis showed that these sites were significantly enriched for the well-documented p53-binding motif (fig. S4A). We next integrated the RNA-seq and ChIP-seq results. The RNA-seq data detected the expression of about 18,000 genes, of which 807 (4.7\%) were identified by ChIP-seq as p53 targets. Notably, p53 target genes were significantly enriched among the IR-induced genes: of the 299 induced genes at 4 hours after IR, 138

A

hrx: $\quad 134,557,000|\quad 134,558,000| \quad 134,559,0001 \quad 134,560,0001 \quad 134,561,0001 \quad 134,562,0001 \quad$ hg19

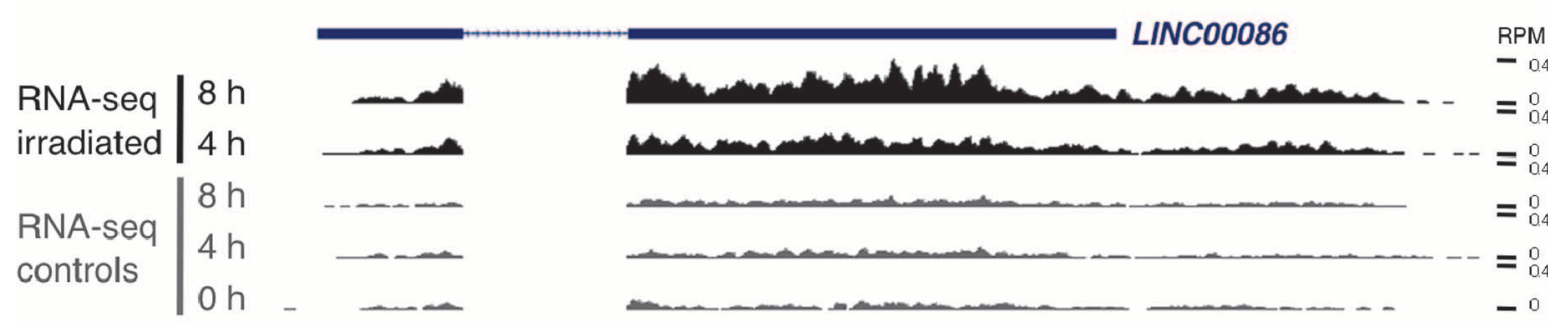

B

LINC00086

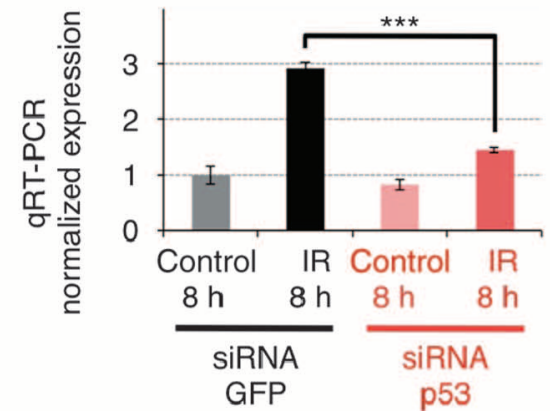

RP3-510D11.2

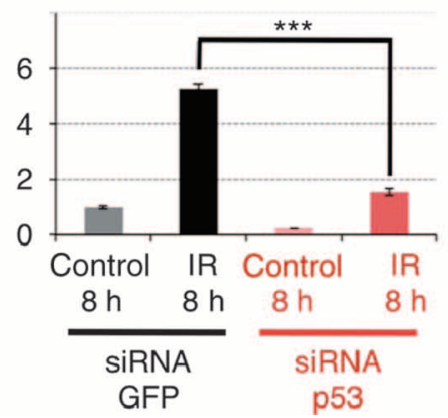

chr9:139,000,925-139,004,533

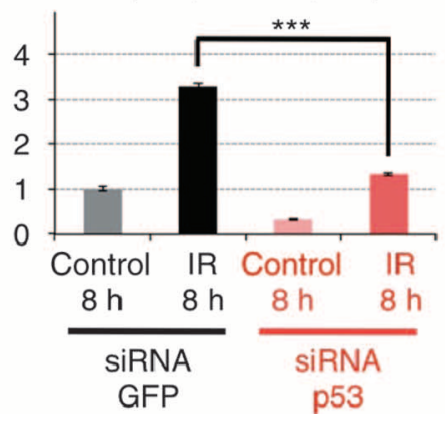

Fig. 4. IR-induced IncRNAs. (A) Example of the IR-induced IncRNA LINC00086 detected by RNA-seq in CAL51 cells after irradiation. (B) qRT-PCR assessment of the effect of p53 knockdown on the IR-induced expression of IncRNAs in CAL51 cells. Data are means \pm SEM of independent triplicate. ${ }^{* *} P<0.0001$, one-tailed $t$ test. 
genes (46\%) were detected by ChIP-seq as p53 targets (about 10-fold enrichment) (Fig. 5B and table S8B). Similar enrichment was observed for the genes induced at 8 hours (fig. S4B). In sharp contrast, the set of IRrepressed genes, whose repression was largely p53-dependent, was not enriched for p53 targets (Fig. 5B and fig. S4B), indicating that most of the genes repressed in a p53-dependent manner were not direct targets of p53, and their response was probably mediated by transcription regulators whose genes could be p53 targets. We identified six genes encoding transcription factors among the IR-induced p53 direct targets, and validated two of them, E2F7 and FOSL1, at both the mRNA and protein levels (fig. $\mathrm{S} 5, \mathrm{~A}$ and B). E2F7, the gene which was recently identified as a direct p53 target (36), is an atypical member of the E2F family of transcription factors. It binds and represses a multitude of cell cycle genes to promote cell cycle arrest and limit malignant transformation by enhancing oncogeneinduced senescence $(36,37)$. FOSL1 is a member of the FOS family of transcription factors, whose role in the DDR is still unclear. Notably, IRinduced p53 binding was also detected near the promoters of five of the eight IR-induced lncRNAs, flagging them as newly identified p53 direct target genes in the DDR (fig. S4C and table S7). Despite the significant enrichment for direct p53 targets among the IR-induced genes, most (about $85 \%$ ) of the p53 targets that were detected using ChIP-seq did not respond to IR (Fig. 5B). For example, the expression of only about $20 \%$ of p53 target genes was induced by more than 1.41-fold (corresponding to 0.5 on the $\log _{2}$-scaled $x$ axis in fig. S6A). Two factors significantly correlated with the actual responsiveness of p53-binding genes: the strength of $\mathrm{p} 53$ binding as reflected in the magnitude of p53-binding peaks, where responding genes were associated with significantly stronger p53 binding (Fig. 6A), and the distance between the p53-binding site and the TSS of the target gene, which was significantly shorter in the responsive genes than in the nonresponsive ones (Fig. 6B and fig. S6B).

\section{The NF-kB component of the IR response}

The small p53-independent gene cluster contained several genes that encode key players in the NF-кB pathways (cluster 4 in Fig. 2A). ChIP-seq analysis of IR-induced genomic binding of the RelA subunit of NF- $\kappa \mathrm{B}$ identified 1511 such events (FDR $=5 \%$ ). These IR-induced RelA binding sites were associated with 807 genes (table S9A). The corresponding binding regions were significantly enriched for the NF- $\mathrm{BB}$ binding signature (fig. S7A). Whereas the extent of IR-induced binding of RelA across the genome was generally similar to that observed for $\mathrm{p} 53$, its effect on target gene expression was much lower. Only $12.4 \%$ (37 genes) of the IRinduced genes were detected as functional RelA targets (table S9B). Although this represents a threefold enrichment of RelA targets among the IR-induced genes (fig. S7, B and C), this enrichment was considerably lower than that of p53 targets ( $46 \%$ of the IR-induced genes at 4 hours after irradiation were detected as direct p53 targets). Significantly, 67\% (12 of 19 genes) of the cluster of p53-independent IR-induced genes were detected as direct RelA targets (fig. S7D), demonstrating the role of NF- $\mathrm{BB}$ in the induction of this response. In contrast to the $\mathrm{p} 53$-dependent induction of proapoptotic genes, this cluster contained two genes, BIRC3 and TNFAIP3, encoding antiapoptotic proteins. Baculoviral IAP repeat-containing 3 (BIRC3) is an E3 ubiquitin ligase that targets caspase 3 and caspase 7 and the TNF receptor-associated
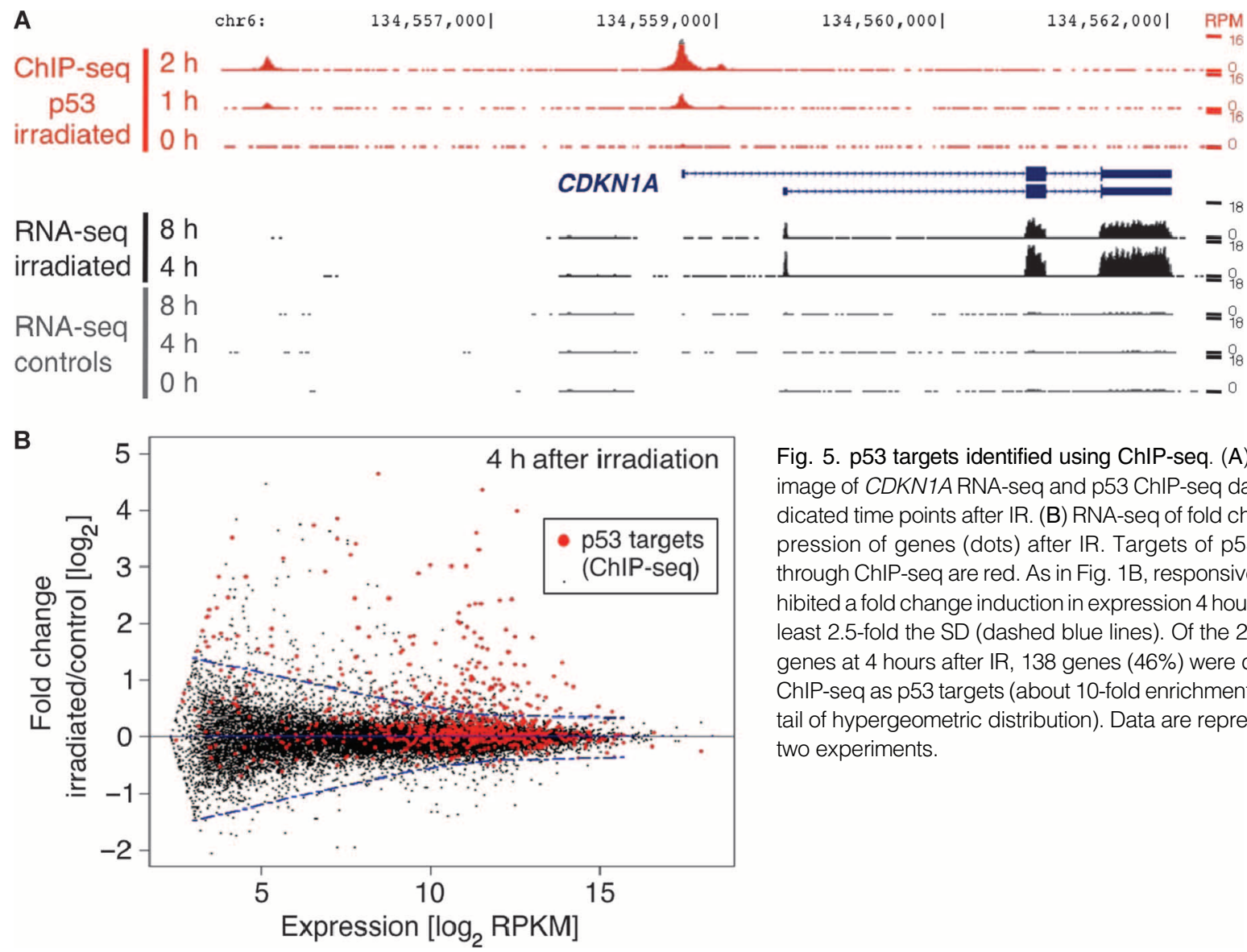

Fig. 5. p53 targets identified using ChIP-seq. (A) Integrated image of CDKN1A RNA-seq and p53 ChIP-seq data at the indicated time points after IR. (B) RNA-seq of fold change in expression of genes (dots) after IR. Targets of p53 identified through ChIP-seq are red. As in Fig. 1B, responsive genes exhibited a fold change induction in expression 4 hours after IR at least 2.5-fold the SD (dashed blue lines). Of the 299 induced genes at 4 hours after IR, 138 genes (46\%) were detected by ChIP-seq as p53 targets (about 10-fold enrichment; $P<10^{-99}$, tail of hypergeometric distribution). Data are representative of two experiments. 
factors TRAF1 and TRAF2, accounting for BIRC3-mediated inhibition of apoptotic signals $(38,39)$. TNF $\alpha$-induced protein 3 (TNFAIP3) protects cells from TNF-induced apoptosis by disrupting the recruitment of the death domain signaling molecules TRADD [TNF receptor superfamily $1 \mathrm{~A}$ (TNFRSF1A)-associated death domain] and the kinase RIP (receptorinteracting protein) to the TNF receptor signaling complex $(40,41)$.

The NF- $\kappa \mathrm{B}$-induced gene cluster exhibited rapid induction promptly followed by a decline (cluster 4 in Fig. 2). We validated this kinetic pattern using qRT-PCR applied to four known NF- $\mathrm{B}$ target genes (fig. S7E). Notably, a similar kinetic pattern was previously observed for NF- $\mathrm{KB}$ targets in activated macrophages (42). In macrophages, activating transcription factor 3 (ATF3) was identified as a transcriptional repressor that mediated the rapid decline in expression of NF- $\mathrm{BB}$ target genes after their induction by immune stimulation. ATF3 expression was also strongly induced in our data set (fig. S7F), suggesting that the NF- $\kappa \mathrm{B}-\mathrm{ATF} 3$ regulatory module is activated by various stresses (fig. $\mathrm{S} 7 \mathrm{G}$ ).

\section{Dynamics of histone marks}

Because regulation of transcription involves dynamic modulation of histone PTMs, we examined the effect of IR on two key histone modifications: trimethylated and monomethylated histone $\mathrm{H} 3 \mathrm{Lys}^{4}$ ( $\mathrm{H} 3 \mathrm{~K} 4 \mathrm{me} 3$ and $\mathrm{H} 3 \mathrm{~K} 4 \mathrm{me}$, respectively). The former marks active promoters, whereas the latter marks enhancer regions $(43,44)$. Using ChIP-seq, we profiled $\mathrm{H} 3 \mathrm{~K} 4 \mathrm{me} 3$ in irradiated and control cells. When these results were integrated with our RNA-seq data, the extent of $\mathrm{H} 3 \mathrm{~K} 4 \mathrm{me} 3$ at gene promoters indeed correlated with gene expression (fig. S8). IR-induced gene activation was also associated with increased $\mathrm{H} 3 \mathrm{~K} 4 \mathrm{me} 3$ downstream of the TSS (Fig. 7A). Because we found that the transcriptional response to IR in CAL51 was primarily ATM-dependent, we examined how the dynamic modulation of H3K4me3 in promoters of IR-induced genes was affected by treatment with the ATM inhibitor KU-55933. ATM inhibition abolished the IR-induced increase in $\mathrm{H} 3 \mathrm{~K} 4 \mathrm{me}$, suggesting that epigenetic modulation at IR-activated promoters is regulated by ATM (Fig. 7, B and C).
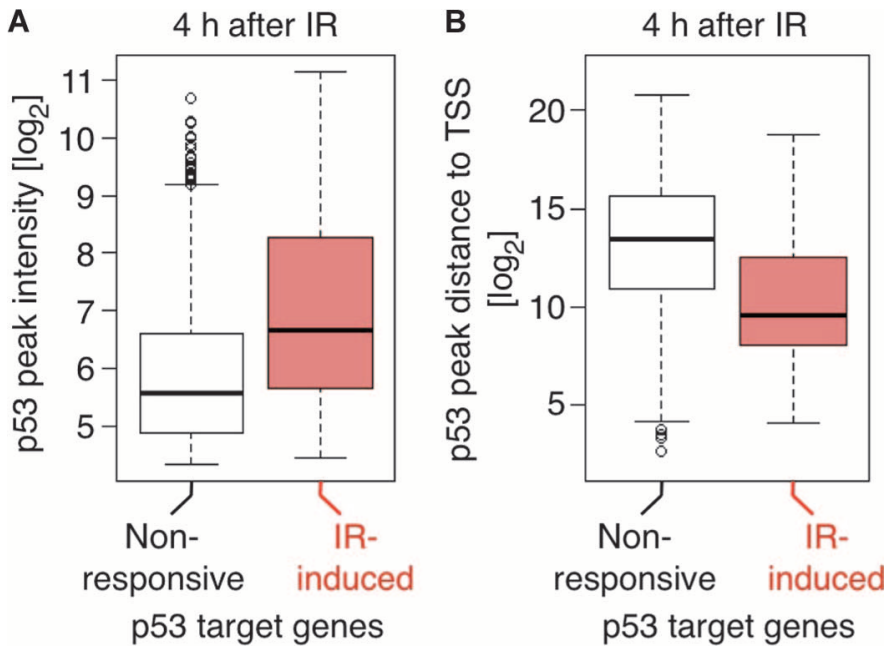

Fig. 6. Factors affecting the responsiveness of p53 targets. (A) Comparison of the extent of p53 binding, indicated by ChIP-seq peak intensity to p53 target genes that did or did not respond to IR. $P=3.4 \times 10^{-20}$, Wilcoxon test. (B) Comparison of the location of p53-binding sites with respect to the TSS in p53 target genes that were induced by IR and in those that were not. $P=$ $9.8 \times 10^{-18}$, Wilcoxon test. Data show the distribution of binding intensity (A) or distance $(B)$.
To examine epigenetic modulation of enhancer signals, we profiled $\mathrm{H} 3 \mathrm{~K} 4 \mathrm{mel}$ in irradiated and unirradiated cells. Notably, this enhancer mark was elevated in a region spanning several hundred base pairs surrounding IR-induced p53-binding sites, and this increased signal was pronounced in cells even before exposure to IR. Furthermore, the H3K4me1 signal was decreased after IR at the location of p53-binding sites (Fig. 8, A and B). This decrease in $\mathrm{H} 3 \mathrm{~K} 4 \mathrm{mel}$ probably reflects nucleosome displacement associated with the IR-induced binding of p53 to these enhancer regions. H3K4me1 dynamics at p53-binding sites was ATM-dependent (Fig. 8C), similar to that of $\mathrm{H} 3 \mathrm{~K} 4 \mathrm{me} 3$.

We then examined the profiles of these histone marks at TSSs of the IRinduced lncRNAs that we had validated. A strong H3K4me3 signal was detected at the bidirectional IR-induced promoter from which the IncRNA $R P 3-510 D 11.2$ and the primary $m i R-34 a$ transcripts are divergently transcribed (fig. S9A). Notably, a 3-kb genomic region spanning the nonannotated IR-induced lncRNA on chromosome 9q34 was strongly enriched for the H3K4me1 signal (fig. S9B), further suggesting that this transcript is an eRNA.

\section{Comparison between RNA-seq and expression microarrays}

Here, we used both expression microarrays and RNA-seq to profile cellular responses to IR. Overall, there was a high correlation between gene expression estimates obtained by these two technologies, except for the lowly expressed genes (fig. S10A). Sensitivity in detection of lowly expressed genes is a major advantage of RNA-seq (45). Consequently, RNA-seq detected a considerably higher number of IR-responsive genes compared with the microarrays (fig. S10B). Notably, IR-induced genes identified solely by RNA-seq were characterized by lower transcript abundance compared with those identified by both technologies (fig. S10, C and D). In addition, RNAseq has a prominent advantage of not being biased toward preselected genes and therefore capable of detecting novel transcripts. Our identification of lncRNAs that were induced by IR in a p53-dependent manner is a typical example.

\section{DISCUSSION}

In the past decade, many studies used expression microarrays to examine transcriptional responses to DNA damage (46-48). Here, we applied mainly RNA-seq, and to a lesser extent expression microarrays, to examine the IR response in CAL51 cells.

Our results highlight the predominance of the ATM-p53 axis in regulating the transcriptional response to IR. The ATM-dependent activation and stabilization of 553 was one of the early signaling pathways to be discovered in the IR response $(49,50)$, and p53 was the first documented physiological target of ATM in the cellular response to DSBs $(51,52)$. ATM regulates $\mathrm{p} 53$ by phosphorylating many other proteins as well, forming a network that meticulously fine-tunes p53 activity and abundance [reviewed by (13)]. In view of the marked dominance of p53 in the IR-induced modulation of gene expression reflected in our data, it is not surprising that $\mathrm{p} 53$ is regulated by ATM with such care and delicacy. Integration of our RNA-seq and p53 ChIP-seq data sets enabled us to classify the genes that responded to IR in a p53-dependent manner as direct or secondary p53 targets, and we conclude that about $50 \%$ of the genes induced in a p53-dependent manner were directly regulated by $\mathrm{p} 53$. It is important to note that this estimate is a lower boundary for the true proportion of direct p 53 targets among the IR-induced genes because we associated p53-binding sites with putative targets only if the sites were located no more than $15 \mathrm{~kb}$ upstream to the TSS, or within the regulated gene. Notably, p53 was shown to regulate gene expression while binding to enhancer regions up to several hundred kilobases from the corresponding TSSs (33). In sharp contrast to the significant enrichment of p53 direct targets among IR-induced genes, only a few IR-repressed 
A Untreated cells, ChIP-seq H3K4me3

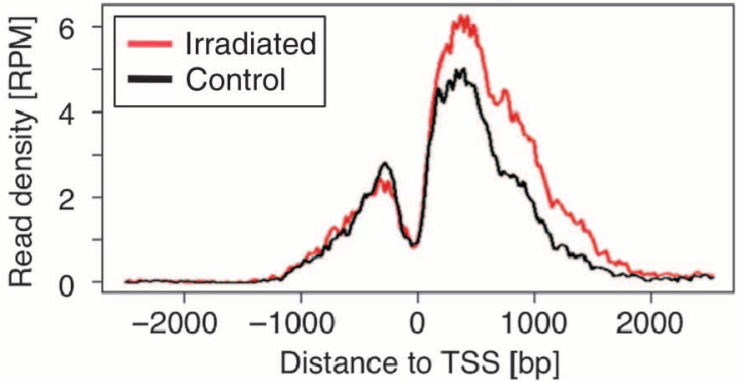

B ATM inhibitor, ChIP-seq H3K4me3

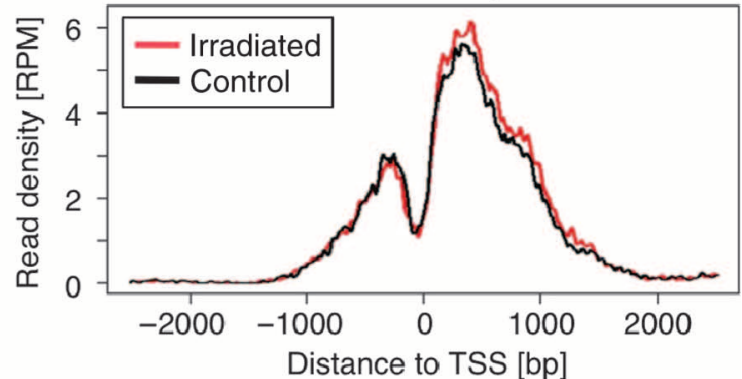

C

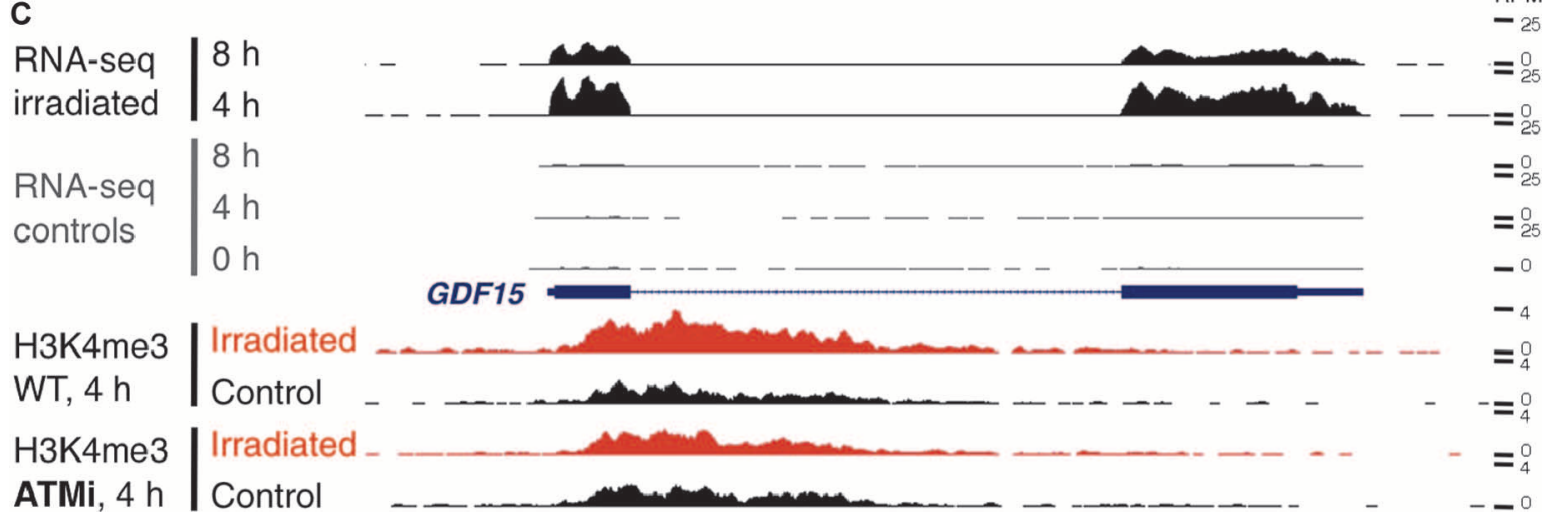

Fig. 7. Alterations in $\mathrm{H} 3 \mathrm{~K} 4 \mathrm{me} 3$ in response to IR. (A) H3K4me3 signals at the promoters of IR-induced genes quantified in unirradiated cells and 4 hours after irradiation as a function of the distance (base pairs) between the signal and the TSS. Data show the mean pattern of the top 50 IR-induced genes. (B) Similar analysis as in (A) in the presence of the ATM inhibitor KU-55933. (C) RNA-seq for the expression of GDF15 and H3K4me3 detection in the GDF15 promoter in response to IR.
A Untreated cells, ChIP-seq H3K4me1

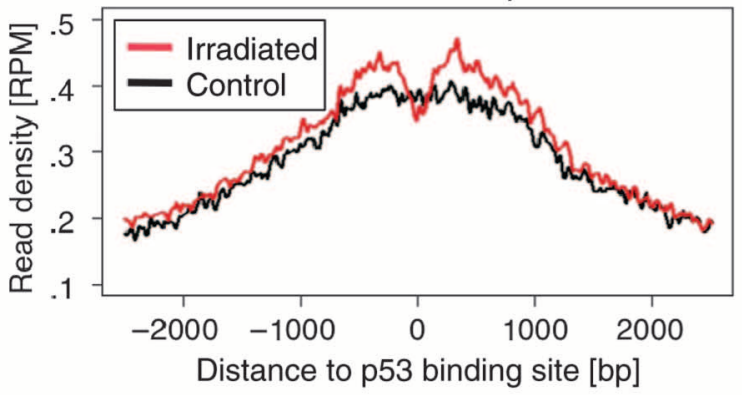

C ATM inhibitor, ChIP-seq H3K4me1

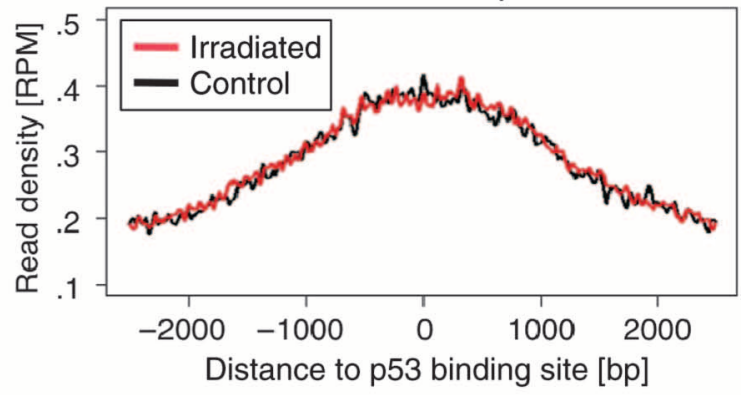

B \begin{tabular}{l|l} 
ChIP-seq & $2 \mathrm{~h}$ \\
p53 irrad. & $\mathrm{h}$ \\
$0 \mathrm{~h}$
\end{tabular}

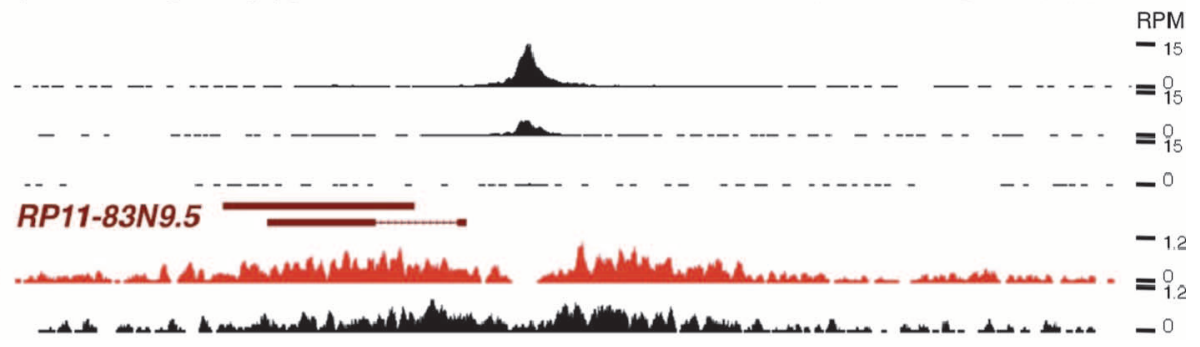

Fig. 8. Alterations in $\mathrm{H} 3 \mathrm{~K} 4 \mathrm{me} 1$ signal in response to IR. (A) Data are the mean $\mathrm{H} 3 \mathrm{~K} 4 \mathrm{me} 1$ signal from all p53-binding regions detected by ChIPseq in unirradiated or irradiated CAL51 cells. (B) ChIP-seq for the bind- ing of p53 to the RP1183N9.5 enhancer alongside H3K4me3 detection at the enhancer in response to IR. (C) Similar experiment and analysis as in (A), cells were treated with the ATM inhibitor before irradiation. 
genes were direct p53 targets, at numbers not exceeding our FDR. Nevertheless, IR-induced gene repression was largely p53-dependent. Our conclusion is that, as opposed to p53-mediated up-regulation, p53dependent gene repression is mostly indirect and carried out by $\mathrm{p} 53-$ dependent regulators. The functional enrichment of the repressed group for cell cycle- and DNA replication-enhancing genes suggests that, in addition to the extensively characterized cell cycle checkpoint mechanisms that act at the protein level (53), the temporary cell cycle arrest that is critical for cell survival while DNA repair takes place is maintained also at the transcriptional level.

Although the enrichment of p53 target genes among the IR-induced genes was remarkable, our analysis shows that most of the IR-induced p53-binding events were not associated with modulation of the expression of the corresponding genes. The high sensitivity of ChIP-seq reveals abundant binding of p53 throughout the genome $[(54,55)$ and this study], as is true for other transcription factors $(56,57)$. However, not all transcription factor binding events are productive. With regard to $\mathrm{p} 53$, our analysis pointed to two factors that determine the degree of this productivity: the affinity of p53 binding and the distance between p53-binding sites and the TSSs. Presumably, binding of various cofactors and p53's rich and dynamic PTM repertoire are other important determinants of the outcome of $\mathrm{p} 53$ binding $(58-60)$. IR is a central cancer treatment modality aimed at depriving tumor cells of their reproductive capacity. This can occur through alternative routes, including induction of apoptosis, senescence, or "mitotic catastrophe," all of which can be invoked in response to DSBs inflicted by IR (61-63). The IR-induced p53 targets in our study were highly enriched for apoptotic genes, highlighting the role of p53 in activating programmed cell death in damaged cells and reflecting its critical role as guardian against tumorigenesis. This critical process is compromised by the loss or inactivation of p53 in a large proportion of tumors. Evidence suggests that in solid tumors that harbor mutated p53, mitotic catastrophe takes over and becomes the major form of cell death induced by radiotherapy $(61,64)$. Yet, a substantial portion of tumors do harbor functional p53, and enhancing p53 activity is an important goal in the treatment of patients with such tumors (65). An example is Nutlin-3, a small molecule that interferes with the interaction of 53 with its major E3 ubiquitin ligase, MDM2 (66). The other pivotal transcription factor that regulated the transcriptional response to IR in our study is NF- $\kappa \mathrm{B}$, whose activation in response to DSB induction is also ATM-dependent and carried out by an ATM-controlled loop involving several proteins [reviewed in (67)]. Contrary to the functional enrichment of proapoptotic genes in the $\mathrm{p} 53$-dependent clusters, the NF- $\mathrm{KB}-$ mediated response contained several key antiapoptotic genes. The concomitant up-regulation of genes involved in these opposing processes, each of which is regulated by a different ATM-activated transcription factor, is interesting. Because our study was carried out on a population of irradiated cells, we cannot tell whether these opposing effectors were induced simultaneously in the same cells, or whether different cells activated different responses, probably in relation to the extent of damage inflicted upon their genome. Emerging technologies for transcriptional profiling in single cells should answer this question. Transcriptional modulation is associated with marked chromatin reorganization and associated dynamics of histone PTMs (68). This dynamics is observed as soon as transcription factors bind to their cognate sites. It was recently shown that in the absence of stress, p53 is already associated with its binding sites within the promoter of the $\mathrm{p} 21$-encoding gene while that genomic region is still nucleosomal. Upon stress, nucleosomes are lost from that region in a p53-dependent manner (69). With custom DNA microarrays, it was similarly observed that, unlike other transcription factors that bind preferably to regions with low nucleosome occupancy, p53 can bind chromatin domains with high intrinsic nucleosome occupancy, and when those domains are activated, nucleosomes are dis- placed from the binding sites (70). Our ChIP-seq analysis of H3K4me1-a marker of enhancers - reflects this phenomenon on a genomic scale. Binding of $\mathrm{p} 53$ to its cognate binding sites produced a clear dip in the H3K4me1 signal. Inhibition of ATM blocked p53 activation and completely abolished the alterations in $\mathrm{H} 3 \mathrm{~K} 4 \mathrm{me} 1$ signals at p53-bound enhancers. Modulation of gene expression is a major component of the DDR. Our data delineate different components of the extensive transcriptional response to DNA damage and highlight its major regulators and their numerous target genes. A recent study undertook an integrated analysis of transcriptomic and phosphoproteomic data to construct a global kinase transcription factor network in the DDR in yeast (16). Our results show that in human CAL51 cells, the transcriptional response is transmitted mainly through three proximal players: the ATM protein kinase and two downstream transcription factors, p53 and NF- $\mathrm{BB}$. Plausibly, additional protein kinases and auxiliary factors downstream of these three players are required for this process (71). Furthermore, recent genomic profiling of DNA damage-induced $\mathrm{p} 53$ binding demonstrated that it is affected by cell type and type of DNA damage $(54,55,72)$. It will be interesting to compare data sets obtained in different combinations of cells and DNA damaging agents using the methodology applied in this study, and identify the common core group of genes that respond to DNA damage and those that are cell type-specific.

\section{MATERIALS AND METHODS}

\section{Cell line and radiation treatment}

CAL51 cells were grown in Dulbecco's modified Eagle's medium supplemented with $10 \%$ fetal bovine serum, and maintained in a humidified, $5 \%$ $\mathrm{CO}_{2}$ atmosphere at $37^{\circ} \mathrm{C}$. Cells were irradiated at a dose rate of $1 \mathrm{~Gy} / \mathrm{min}$ with an MG-165 ion chamber (Philips). After irradiation, cells were incubated for selected time periods at $37^{\circ} \mathrm{C}$. Mock-treated controls were handled identically, excluding irradiation.

\section{TP53 knockdown and ATM inhibition}

TP53 knockdown was obtained with ON-TARGETplus SMARTpool siRNA (Thermo Scientific Dharmacon). ON-TARGETplus siRNA duplex designed against the GFP protein served as negative control. The effectiveness of the knockdown was assessed by measuring both p $53 \mathrm{mRNA}$ and protein abundance with qRT-PCR and Western blotting, respectively. Sequences of RT-PCR primers are provided in table S10. Inhibition of ATM was carried out with the chemical inhibitor KU-55933 (Tocris Biosciences) (73). CAL51 cells were incubated with the ATM inhibitor to a final concentration of $10 \mu \mathrm{M}$ for 1 hour before irradiation.

\section{RNA isolation}

Total RNA was extracted from cells with the RNeasy Plus Mini kit in combination with QIAshredder columns (Qiagen). The integrity of the RNA was assured with gel electrophoresis and on a Bioanalyzer.

\section{RNA library construction and sequencing}

RNA libraries were prepared following a protocol preserving the strand information (74). Poly(A)+ selection was applied to $500 \mathrm{ng}$ of starting total RNA. Library complexities were checked before sequencing. Paired-end sequencing of the resulting strand-specific libraries was carried out with $2 \times 51$ cycles on a HiSeq 2000 instrument (Illumina).

\section{ChIP, library construction, and sequencing}

ChIP was performed with 25 million formaldehyde-cross-linked cells for transcription factor analysis and 10 million cells for histone modification analysis, as described before (75). After cell lysis, the nuclei were collected 
and sonicated in a water bath sonicator (Diagenode Bioruptor) to shear the chromatin to a final size of 200 to $500 \mathrm{bp}$. The sonicated chromatin was cleared by centrifugation for $10 \mathrm{~min}$ with $10,000 \mathrm{~g}$, and $50 \mu \mathrm{l}$ of chromatin was reserved as input sample for later DNA purification in parallel with the ChIP DNA. The cleared chromatin was incubated overnight at $4^{\circ} \mathrm{C}$ with the respective well-characterized ChIP-grade antibody, namely, mouse monoclonal anti-human p53 (DO-1, BD Pharmingen, 554293, $10 \mu \mathrm{g}$ ), rabbit polyclonal anti-NF-кB p65 (C-20X, Santa Cruz Biotechnology, sc-372, $10 \mu \mathrm{g}$ ), rabbit polyclonal anti-H3K4me1 (Abcam, ab8895, $5 \mu \mathrm{g}$ ), and rabbit polyclonal anti-H3K4me3 (Abcam, ab8580, $5 \mu \mathrm{g}$ ). After addition of protein $\mathrm{G}$ magnetic beads (Invitrogen) and two more hours of incubation at $4^{\circ} \mathrm{C}$, the beads were washed and the DNA was eluted, reverse-cross-linked, digested with ribonuclease (RNase) A and proteinase K, phenol-chloroformextracted, and purified by precipitation with Pellet Paint (Novagen, 690493 ) as carrier. The input DNA was purified in parallel. The input and ChIP DNAs (5 ng for transcription factor ChIPs, $20 \mathrm{ng}$ for histone modification ChIPs) were used for preparation of sequencing libraries according to the manufacturer's instructions for the Genome Analyzer GAII instrument (Illumina). After DNA purification with the DNA Clean \& Concentrator-5 kit, the DNA libraries were separated on $2 \%$ agarose TAE gels. The $150-$ to 250-bp fragments were excised from the gel on a Dark Reader (Claire Chemical Research) and purified with a Qiagen MinElute Gel Extraction Kit. Sequencing was performed on a Genome Analyzer GAII instrument (Illumina) with 36 cycles.

\section{qRT-PCR analysis}

Comparisons of the ChIP enrichments and input DNA were calculated from qRT-PCR results as fold enrichments according to the $\Delta \Delta C_{\mathrm{t}}$ method (76). PCR was performed in triplicate using SYBR Green (Applied Biosystems) with ChIP $(20 \mathrm{pg} / \mu \mathrm{l})$ or input DNA and a final primer concentration of 750 $\mathrm{nM}$. Detection primers for known genomic target regions were as follows: MDM2 (a target of TP53), 5'-CGTTCCGAAACTGCAGTAAA-3' (forward) and 5'-CAGCTGGAGACAAGTCAGGA-3' (reverse); ICAM1 (a target of RelA), 5'-GCCGCCCGATTGCTTTAG-3' (forward) and 5'GCTGCAGTTATTTCCGGACTG-3' (reverse); and CDKN1A (for H3K4me1 and H3K4me3), 5'-TGCGTTCACAGGTGTTTCTG-3' (forward) and 5'-CACATCCCGACTCTCGTCAC-3' (reverse). Control primers for background correction were as follows: interleukin-4 (control), 5'-CAAGATGCCACCTGTACTTGGA-3' (forward) and 5'-CCACAGGTGTCCGAATTTGTT-3' (reverse).

\section{Analysis of deep sequencing data}

For RNA-seq, sequenced reads were aligned to the human genome (hg19) with TopHat (77). Gene expression was calculated with HTSeq (78) to count the number of reads that map to each gene, followed by quantile normalization to normalize between different samples. Gene annotations were downloaded from Ensembl. For ChIP-seq, sequenced reads were aligned to the human genome (hg19) with Bowtie (79). IR-induced transcription factor binding sites (IR-induced peaks) were detected with the CisGenome package $(80)$, with the unirradiated sample as control. De novo sequence motif analysis was carried out with MEME (81) and Amadeus (82).

\section{Analysis of gene expression microarray data}

Dense-kinetic expression profiling of CAL51 response to IR $(0,2,4,6,8$, 10, 12, and 24 hours) was performed with Affymetrix HuGene-1_0-st_v1 microarrays. Data were preprocessed with RMA (83) implemented in the Affymetrix Console tool. Effects of ATM inhibition and p53 silencing on CAL51 transcriptional response to IR were probed with Illumina BeadArray chips in independent triplicate and analyzed with Bioconductor's beadarray package (84). Cluster analysis was performed with the CLICK algorithm (85) implemented in EXPANDER (86). GO enrichment analysis was performed with DAVID (87). Pathway analysis used SPIKE (88).

\section{Quantitative RT-PCR}

For SYBR Green qRT-PCR analysis, complementary DNA (cDNA) was produced from $10 \mu \mathrm{g}$ of total RNA with SuperScript II RNase H Reverse Transcriptase (Life Technologies) in the presence of oligo(dT) $)_{15}$ primer (Promega) and random primers mix (Life Technologies) in a total volume of $40 \mu$ l. qPCR with POWER SYBR Green PCR master mix (Applied Biosystems) was performed with ABI PRISM 7900HT sequence detection system (Applied Biosystems). The comparative $C_{\mathrm{t}}$ method was used to quantify transcripts and was measured in triplicate. qPCR primers were designed with the software Primer Express 2.00 on the basis of published sequence data from the National Center for Biotechnology Information database. All assays were carried out in triplicate, and three independent experiments were performed to verify reproducibility. Results were normalized against human TBP expression in each of the samples. For qRT-PCR, we used Custom TaqMan Array 96-well Fast Plates (Applied Biosystems), in which each well contained a TaqMan Gene Expression Assay to a different gene. Each assay contained gene-specific primers and a 6-FAM dye-labeled TaqMan MGB probe. We used a plate format of six sets containing 1 manufacturing control (18S ribosomal RNA) and 15 gene expression assays listed, 2 of which were endogenous controls (Hu-HPRT1 and $\mathrm{Hu}-\mathrm{TBP})$, and the remaining 13 were target genes: AEN-Hs00224322_m1, ANKRA2-Hs01067059_m1, DCP1B-Hs00398931_m1, DDIT4-Hs01111686_g1, FBXO22Hs00201796_m1, FBXW7-Hs00217794_m1, HPRT1-Hs99999909_m1, LRDD-Hs00388035_m1, NOTCH1-Hs01062014_m1, PHLDA3Hs00385313_m1, PMAIP1-Hs00560402_m1, PRDM1-Hs00153357_m1, RNF19B-Hs00415359_m1, SERTAD1-Hs00203547_m1, TBPHs99999910_m1, and 18S-Hs99999901_s1. In each plate, we tested three different cDNA samples, each one in 32 wells; thus, each gene was assayed in duplicate. Amplification was carried out with ABI StepOnePlus PCR System along with TaqMan Fast Universal PCR Master Mix and optical Fast thermal cycling plates (Applied Biosystems; for fast cycling). Each well of the TaqMan Array Plate was reconstituted with a mix of the Fast PCR master mix and a cDNA sample ( $40 \mathrm{ng}$ ) to a final volume of $10 \mu 1$. PCR was performed as follows: $50^{\circ} \mathrm{C}$ for $2 \mathrm{~min}, 95^{\circ} \mathrm{C}$ for $20 \mathrm{~s}$, followed by 45 cycles at $95^{\circ} \mathrm{C}$ for $3 \mathrm{~s}$ and $60^{\circ} \mathrm{C}$ for $30 \mathrm{~s}$. The data were analyzed with ABI StepOne software.

\section{Western blotting analysis}

Equal amounts of protein from cell extracts were separated with $10 \%$ SDS-polyacrylamide gel electrophoresis. Proteins were transferred to nitrocellulose membrane by the electroblot technique. Blots were incubated with the suitable antibodies. Human p53 monoclonal antibody (DO-1), human p21 (H-164) antibody, human E2F7 antibody, and human HSC-70 (B-6) antibody were obtained from Santa Cruz Biotechnology Inc.; human phosphorylated p53 antibody (phospho-p53-Ser ${ }^{15}$ ) and human phosphorylated ATM antibody (phospho-ATM-Ser ${ }^{198}$ ) were obtained from Cell Signaling Technology Inc.; human ATM antibody (Mat3) was produced by Sigma-Aldrich; human phosphorylated KAP1 antibody (phospho-KAP1-Ser ${ }^{824}$ ) was obtained from Bethyl Laboratories Inc.; human FRA-1 antibody was obtained from R\&D Systems; and human RelA subunit of NF- $\mathrm{KB}$ (p65) antibody was obtained from BioVision Inc. Horseradish peroxidase-conjugated antibodies (Jackson ImmunoResearch Laboratories Inc.) were used for detecting the antibody binding.

\section{Cell cycle analysis}

Flow cytometry analysis was carried out with a FACSCalibur flow cytometer (Becton Dickinson), and the data were analyzed with FCS Express 4.0 (De Novo Software). 


\section{SUPPLEMENTARY MATERIALS}

www.sciencesignaling.org/cgi/content/full/7/325/rs3/DC1

Fig. S1. IR-induced responses in CAL51 cells.

Fig. S2. p53-dependent transcriptional response to IR in CAL51 cells.

Fig. S3. Induction of noncoding RNAs by IR.

Fig. S4. ChIP-seq analysis for p53.

Fig. S5. Secondary transcription factors induced by IR

Fig. S6. Responsiveness of p53 target genes to IR.

Fig. S7. ChIP-seq analysis for RelA.

Fig. S8. Relationship between gene expression and H3K4me3 abundance in promoters.

Fig. S9. Histone marks near IR-induced IncRNAs.

Fig. S10. Improved detection of weakly expressed genes by RNA-seq versus microarray

Table S1. Early and late kinetics of IR-induced clusters (expression microarrays).

Table S2. RNA-seq number of reads.

Table S3. IR-responsive genes (RNA-seq).

Table S4. GO analysis of the responsive genes.

Table S5. RNA-seq expression matrix.

Table S6. Microarray expression matrix.

Table S7. IR-induced IncRNAs.

Table S8. IR-induced p53-binding sites.

Table S9. IR-induced RelA binding sites.

Table S10. Sequences of RT-PCR primers.

\section{REFERENCES AND NOTES}

1. T. Lindahl, Instability and decay of the primary structure of DNA. Nature $\mathbf{3 6 2}, 709-715$ (1993).

2. A. Ciccia, S. J. Elledge, The DNA damage response: Making it safe to play with knives. Mol. Cell 40, 179-204 (2010).

3. L. H. Thompson, Recognition, signaling, and repair of DNA double-strand breaks produced by ionizing radiation in mammalian cells: The molecular choreography Mutat. Res. 751, 158-246 (2012).

4. D. K. Jeppesen, V. A. Bohr, T. Stevnsner, DNA repair deficiency in neurodegeneration. Prog. Neurobiol. 94, 166-200 (2011).

5. M. O'Driscoll, Diseases associated with defective responses to DNA damage. Cold Spring Harb. Perspect. Biol. 4, a012773 (2012).

6. S. Negrini, V. G. Gorgoulis, T. D. Halazonetis, Genomic instability-An evolving hallmark of cancer. Nat. Rev. Mol. Cell Biol. 11, 220-228 (2010)

7. J. Vijg, Y. Suh, Genome instability and aging. Annu. Rev. Physiol. 75, 645-668 (2013).

8. K. Aziz, S. Nowsheen, G. Pantelias, G. lliakis, V. G. Gorgoulis, A. G. Georgakilas, Targeting DNA damage and repair: Embracing the pharmacological era for successfu cancer therapy. Pharmacol. Ther. 133, 334-350 (2012).

9. B. Basu, T. A. Yap, L. R. Molife, J. S. de Bono, Targeting the DNA damage response in oncology: Past, present and future perspectives. Curr. Opin. Oncol. 24, 316-324 (2012).

10. B. M. Sirbu, D. Cortez, DNA damage response: Three levels of DNA repair regulation. Cold Spring Harb. Perspect. Biol. 5, a012724 (2013).

11. V. Borde, B. de Massy, Programmed induction of DNA double strand breaks during meiosis: Setting up communication between DNA and the chromosome structure. Curr. Opin. Genet. Dev. 23, 147-155 (2013).

12. F. W. Alt, Y. Zhang, F. L. Meng, C. Guo, B. Schwer, Mechanisms of programmed DNA lesions and genomic instability in the immune system. Cell 152, 417-429 (2013)

13. Y. Shiloh, Y. Ziv, The ATM protein kinase: Regulating the cellular response to genotoxic stress, and more. Nat. Rev. Mol. Cell Biol. 14, 197-210 (2013).

14. S. E. Polo, S. P. Jackson, Dynamics of DNA damage response proteins at DNA breaks: A focus on protein modifications. Genes Dev. 25, 409-433 (2011).

15. S. Bandyopadhyay, M. Mehta, D. Kuo, M. K. Sung, R. Chuang, E. J. Jaehnig, B. Bodenmiller, K. Licon, W. Copeland, M. Shales, D. Fiedler, J. Dutkowski, A. Guénolé, H. van Attikum, K. M. Shokat, R. D. Kolodner, W. K. Huh, R. Aebersold, M. C. Keogh, N. J. Krogan, T. Ideker, Rewiring of genetic networks in response to DNA damage. Science $\mathbf{3 3 0}$ 1385-1389 (2010).

16. E. J. Jaehnig, D. Kuo, H. Hombauer, T. G. Ideker, R. D. Kolodner, Checkpoint kinases regulate a global network of transcription factors in response to DNA damage. Cell Rep. 4, 174-188 (2013).

17. A. Guénolé, R. Srivas, K. Vreeken, Z. Z. Wang, S. Wang, N. J. Krogan, T. Ideker, H. van Attikum, Dissection of DNA damage responses using multiconditional genetic interaction maps. Mol. Cell 49, 346-358 (2013).

18. L. von Stechow, B. van de Water, E. H. Danen, Unraveling DNA damage responsesignaling networks through systems approaches. Arch. Toxicol. 87, 1635-1648 (2013)

19. W. P. Roos, B. Kaina, DNA damage-induced cell death: From specific DNA lesions to the DNA damage response and apoptosis. Cancer Lett. 332, 237-248 (2013).

20. F. Ozsolak, P. M. Milos, RNA sequencing: Advances, challenges and opportunities. Nat. Rev. Genet. 12, 87-98 (2011).
21. T. S. Furey, ChIP-seq and beyond: New and improved methodologies to detect and characterize protein-DNA interactions. Nat. Rev. Genet. 13, 840-852 (2012).

22. P. J. Park, ChIP-seq: Advantages and challenges of a maturing technology. Nat. Rev. Genet. 10, 669-680 (2009)

23. J. Gioanni, D. Le François, E. Zanghellini, C. Mazeau, F. Ettore, J. C. Lambert, M. Schneider, B. Dutrillaux, Establishment and characterisation of a new tumorigenic cell line with a normal karyotype derived from a human breast adenocarcinoma. Br. J. Cancer 62, 8-13 (1990).

24. T. Kawase, H. Ichikawa, T. Ohta, N. Nozaki, F. Tashiro, R. Ohki, Y. Taya, p53 target gene AEN is a nuclear exonuclease required for p53-dependent apoptosis. Oncogene 27, 3797-3810 (2008).

25. K. G. Eby, J. M. Rosenbluth, D. J. Mays, C. B. Marshall, C. E. Barton, S. Sinha, K. N. Johnson, L. Tang, J. A. Pietenpol, ISG20L1 is a p53 family target gene that modulates genotoxic stress-induced autophagy. Mol. Cancer 9, 95 (2010)

26. R. Pick, S. Badura, S. Bösser, M. Zörnig, Upon intracellular processing, the C-terminal death domain-containing fragment of the p53-inducible PIDD/LRDD protein translocates to the nucleoli and interacts with nucleolin. Biochem. Biophys. Res. Commun. 349, 1329-1338 (2006).

27. T. Kawase, R. Ohki, T. Shibata, S. Tsutsumi, N. Kamimura, J. Inazawa, T. Ohta, H. Ichikawa, H. Aburatani, F. Tashiro, Y. Taya, PH domain-only protein PHLDA3 is a p53-regulated repressor of Akt. Cell 136, 535-550 (2009).

28. I. Ulitsky, D. P. Bartel, lincRNAs: Genomics, evolution, and mechanisms. Cell 154, 26-46 (2013).

29. P. J. Batista, H. Y. Chang, Long noncoding RNAs: Cellular address codes in development and disease. Cell 152, 1298-1307 (2013)

30. J. L. Rinn, H. Y. Chang, Genome regulation by long noncoding RNAs. Annu. Rev. Biochem. 81, 145-166 (2012)

31. F. Loayza-Puch, J. Drost, K. Rooijers, R. Lopes, R. Elkon, R. Agami, p53 induces transcriptional and translational programs to suppress cell proliferation and growth Genome Biol. 14, R32 (2013)

32. T. K. Kim, M. Hemberg, J. M. Gray, A. M. Costa, D. M. Bear, J. Wu, D. A. Harmin, M. Laptewicz, K. Barbara-Haley, S. Kuersten, E. Markenscoff-Papadimitriou, D. Kuhl, H. Bito, P. F. Worley, G. Kreiman, M. E. Greenberg, Widespread transcription at neuronal activity-regulated enhancers. Nature 465, 182-187 (2010).

33. C. A. Melo, J. Drost, P. J. Wijchers, H. van de Werken, E. de Wit, J. A. Oude Vrielink R. Elkon, S. A. Melo, N. Léveillé, R. Kalluri, W. de Laat, R. Agami, eRNAs are required for p53-dependent enhancer activity and gene transcription. Mol. Cell 49, 524-535 (2013).

34. L. He, X. He, L. P. Lim, E. de Stanchina, Z. Xuan, Y. Liang, W. Xue, L. Zender, J. Magnus D. Ridzon, A. L. Jackson, P. S. Linsley, C. Chen, S. W. Lowe, M. A. Cleary, G. J. Hannon, A microRNA component of the p53 tumour suppressor network. Nature 447, 1130-1134 (2007).

35. N. Raver-Shapira, E. Marciano, E. Meiri, Y. Spector, N. Rosenfeld, N. Moskovits, Z. Bentwich M. Oren, Transcriptional activation of miR-34a contributes to p53-mediated apoptosis. Mol. Cell 26, 731-743 (2007).

36. L. A. Carvajal, P. J. Hamard, C. Tonnessen, J. J. Manfredi, E2F7, a novel target, is upregulated by $\mathrm{p} 53$ and mediates DNA damage-dependent transcriptional repression. Genes Dev. 26, 1533-1545 (2012).

37. O. Aksoy, A. Chicas, T. Zeng, Z. Zhao, M. McCurrach, X. Wang, S. W. Lowe, The atypical E2F family member E2F7 couples the p53 and RB pathways during cellular senescence. Genes Dev. 26, 1546-1557 (2012)

38. A. Busca, M. Saxena, A. Kumar, Critical role for antiapoptotic Bcl-xL and $\mathrm{Mcl}-1$ in human macrophage survival and cellular IAP1/2 (cIAP1/2) in resistance to HIV-Vprinduced apoptosis. J. Biol. Chem. 287, 15118-15133 (2012).

39. S. Cohen, I. Bruchim, D. Graiver, Z. Evron, V. Oron-Karni, M. Pasmanik-Chor, R. Eitan, J. Bernheim, H. Levavi, A. Fishman, E. Flescher, Platinum-resistance in ovarian cancer cells is mediated by IL- 6 secretion via the increased expression of its target clAP-2. J. Mol. Med. 91, 357-368 (2013).

40. K. L. He, A. T. Ting, A20 inhibits tumor necrosis factor (TNF) alpha-induced apoptosis by disrupting recruitment of TRADD and RIP to the TNF receptor 1 complex in Jurkat T cells. Mol. Cell. Biol. 22, 6034-6045 (2002).

41. J. A. Vendrell, S. Ghayad, S. Ben-Larbi, C. Dumontet, N. Mechti, P. A. Cohen, A20/ TNFAIP3, a new estrogen-regulated gene that confers tamoxifen resistance in breast cancer cells. Oncogene 26, 4656-4667 (2007).

42. M. Gilchrist, V. Thorsson, B. Li, A. G. Rust, M. Korb, J. C. Roach, K. Kennedy, T. Hai, H. Bolouri, A. Aderem, Systems biology approaches identify ATF3 as a negative regulator of Toll-like receptor 4. Nature 441, 173-178 (2006).

43. N. D. Heintzman, G. C. Hon, R. D. Hawkins, P. Kheradpour, A. Stark, L. F. Harp, Z. Ye, L. K. Lee, R. K. Stuart, C. W. Ching, K. A. Ching, J. E. Antosiewicz-Bourget, H. Liu, X. Zhang, R. D. Green, V. V. Lobanenkov, R. Stewart, J. A. Thomson, G. E. Crawford, M. Kellis B. Ren, Histone modifications at human enhancers reflect global cell-type-specific gene expression. Nature 459, 108-112 (2009).

44. S. L. Berger, The complex language of chromatin regulation during transcription. Nature 447, 407-412 (2007)

45. Z. Wang, M. Gerstein, M. Snyder, RNA-Seq: A revolutionary tool for transcriptomics. Nat. Rev. Genet. 10, 57-63 (2009). 
46. S. Rashi-Elkeles, R. Elkon, N. Weizman, C. Linhart, N. Amariglio, G. Sternberg, G. Rechavi, A. Barzilai, R. Shamir, Y. Shiloh, Parallel induction of ATM-dependent pro- and antiapoptotic signals in response to ionizing radiation in murine lymphoid tissue. Oncogene $\mathbf{2 5}$, 1584-1592 (2006).

47. S. A. Amundson, M. Bittner, A. J. Fornace Jr., Functional genomics as a window on radiation stress signaling. Oncogene 22, 5828-5833 (2003).

48. L. Roy, G. Gruel, A. Vaurijoux, Cell response to ionising radiation analysed by gene expression patterns. Ann. Ist. Super. Sanita 45, 272-277 (2009).

49. M. B. Kastan, O. Onyekwere, D. Sidransky, B. Vogelstein, R. W. Craig, Participation of p53 protein in the cellular response to DNA damage. Cancer Res. 51, 6304-6311 (1991).

50. M. B. Kastan, Q. Zhan, W. S. el-Deiry, F. Carrier, T. Jacks, W. V. Walsh, B. S. Plunkett, B. Vogelstein, A. J. Fornace Jr., A mammalian cell cycle checkpoint pathway utilizing p53 and GADD45 is defective in ataxia-telangiectasia. Cell 71, 587-597 (1992)

51. C. E. Canman, D. S. Lim, K. A. Cimprich, Y. Taya, K. Tamai, K. Sakaguchi, E. Appella, M. B. Kastan, J. D. Siliciano, Activation of the ATM kinase by ionizing radiation and phosphorylation of p53. Science 281, 1677-1679 (1998).

52. S. Banin, L. Moyal, S. Shieh, Y. Taya, C. W. Anderson, L. Chessa, N. I. Smorodinsky, C. Prives, Y. Reiss, Y. Shiloh, Y. Ziv, Enhanced phosphorylation of p53 by ATM in response to DNA damage. Science 281, 1674-1677 (1998).

53. K. Finn, N. F. Lowndes, M. Grenon, Eukaryotic DNA damage checkpoint activation in response to double-strand breaks. Cell. Mol. Life Sci. 69, 1447-1473 (2012).

54. K. Botcheva, S. R. McCorkle, W. R. McCombie, J. J. Dunn, C. W. Anderson, Distinct p53 genomic binding patterns in normal and cancer-derived human cells. Cell Cycle 10, 4237-4249 (2011).

55. F. Nikulenkov, C. Spinnler, H. Li, C. Tonelli, Y. Shi, M. Turunen, T. Kivioja, I. Ignatiev, A. Kel, J. Taipale, G. Selivanova, Insights into p53 transcriptional function via genomewide chromatin occupancy and gene expression analysis. Cell Death Differ. 19, 1992-2002 (2012).

56. G. Robertson, M. Hirst, M. Bainbridge, M. Bilenky, Y. Zhao, T. Zeng, G. Euskirchen, B. Bernier, R. Varhol, A. Delaney, N. Thiessen, O. L. Griffith, A. He, M. Marra, M. Snyder, S. Jones, Genome-wide profiles of STAT1 DNA association using chromatin immunoprecipitation and massively parallel sequencing. Nat. Methods 4, 651-657 (2007).

57. ENCODE Project Consortium, B. E. Bernstein, E. Birney, I. Dunham, E. D. Green, C. Gunter, M. Snyder, An integrated encyclopedia of DNA elements in the human genome. Nature 489, 57-74 (2012).

58. K. T. Bieging, L. D. Attardi, Deconstructing p53 transcriptional networks in tumor suppression. Trends Cell Biol. 22, 97-106 (2012).

59. H. C. Reinhardt, B. Schumacher, The p53 network: Cellular and systemic DNA damage responses in aging and cancer. Trends Genet. 28, 128-136 (2012).

60. K. D. Sullivan, C. L. Gallant-Behm, R. E. Henry, J. L. Fraikin, J. M. Espinosa, The p53 circuit board. Biochim. Biophys. Acta 1825, 229-244 (2012).

61. D. Eriksson, T. Stigbrand, Radiation-induced cell death mechanisms. Tumour Biol. 31, 363-372 (2010).

62. H. Vakifahmetoglu, M. Olsson, B. Zhivotovsky, Death through a tragedy: Mitotic catastrophe. Cell Death Differ. 15, 1153-1162 (2008).

63. O. Surova, B. Zhivotovsky, Various modes of cell death induced by DNA damage. Oncogene 32, 3789-3797 (2013).

64. I. B. Roninson, E. V. Broude, B. D. Chang, If not apoptosis, then what? Treatmentinduced senescence and mitotic catastrophe in tumor cells. Drug Resist. Updat. 4 , 303-313 (2001).

65. D. P. Lane, C. F. Cheok, S. Lain, p53-based cancer therapy. Cold Spring Harb. Perspect. Biol. 2, a001222 (2010).

66. M. Lu, H. Breyssens, V. Salter, S. Zhong, Y. Hu, C. Baer, I. Ratnayaka, A. Sullivan, N. R. Brown, J. Endicott, S. Knapp, B. M. Kessler, M. R. Middleton, C. Siebold, E. Y. Jones, E. V. Sviderskaya, J. Cebon, T. John, O. L. Caballero, C. R. Goding, X. Lu, Restoring p53 function in human melanoma cells by inhibiting MDM2 and cyclin B1/CDK1-phosphorylated nuclear iASPP. Cancer Cell 23, 618-633 (2013).

67. K. W. McCool, S. Miyamoto, DNA damage-dependent NF-kB activation: NEMO turns nuclear signaling inside out. Immunol. Rev. 246, 311-326 (2012).

68. A. J. Bannister, T. Kouzarides, Regulation of chromatin by histone modifications. Cell Res. 21, 381-395 (2011)

69. O. Laptenko, R. Beckerman, E. Freulich, C. Prives, p53 binding to nucleosomes within the p21 promoter in vivo leads to nucleosome loss and transcriptional activation. Proc. Natl. Acad. Sci. U.S.A. 108, 10385-10390 (2011).

70. E. Lidor Nili, Y. Field, Y. Lubling, J. Widom, M. Oren, E. Segal, p53 binds preferentially to genomic regions with high DNA-encoded nucleosome occupancy. Genome Res. 20, 1361-1368 (2010).

71. A. Bensimon, R. Aebersold, Y. Shiloh, Beyond ATM: The protein kinase landscape of the DNA damage response. FEBS Lett. 585, 1625-1639 (2011).

72. D. Menendez, T. A. Nguyen, J. M. Freudenberg, V. J. Mathew, C. W. Anderson, R. Jothi, M. A. Resnick, Diverse stresses dramatically alter genome-wide p53 binding and transactivation landscape in human cancer cells. Nucleic Acids Res. 41, 7286-7301 (2013).
73. I. Hickson, Y. Zhao, C. J. Richardson, S. J. Green, N. M. Martin, A. I. Orr, P. M. Reaper, S. P. Jackson, N. J. Curtin, G. C. Smith, Identification and characterization of a novel and specific inhibitor of the ataxia-telangiectasia mutated kinase ATM. Cancer Res. 64, 9152-9159 (2004)

74. M. Sultan, S. Dökel, V. Amstislavskiy, D. Wuttig, H. Sültmann, H. Lehrach, M. L. Yaspo, A simple strand-specific RNA-Seq library preparation protocol combining the Illumina TruSeq RNA and the dUTP methods. Biochem. Biophys. Res. Commun. 422, 643-646 (2012).

75. H. J. Warnatz, D. Schmidt, T. Manke, I. Piccini, M. Sultan, T. Borodina, D. Balzereit, W. Wruck, A. Soldatov, M. Vingron, H. Lehrach, M. L. Yaspo, The BTB and CNC homology $1(\mathrm{BACH} 1)$ target genes are involved in the oxidative stress response and in control of the cell cycle. J. Biol. Chem. 286, 23521-23532 (2011).

76. K. J. Livak, T. D. Schmittgen, Analysis of relative gene expression data using real-time quantitative PCR and the $2^{-\Delta \Lambda C T}$ method. Methods 25, 402-408 (2001).

77. C. Trapnell, L. Pachter, S. L. Salzberg, TopHat: Discovering splice junctions with RNA-Seq. Bioinformatics 25, 1105-1111 (2009).

78. S. Anders, D. J. McCarthy, Y. Chen, M. Okoniewski, G. K. Smyth, W. Huber, M. D. Robinson, Count-based differential expression analysis of RNA sequencing data using $R$ and Bioconductor. Nat. Protoc. 8, 1765-1786 (2013).

79. B. Langmead, C. Trapnell, M. Pop, S. L. Salzberg, Ultrafast and memory-efficient alignment of short DNA sequences to the human genome. Genome Biol. 10, R25 (2009).

80. H. Ji, H. Jiang, W. Ma, D. S. Johnson, R. M. Myers, W. H. Wong, An integrated software system for analyzing ChIP-chip and ChIP-seq data. Nat. Biotechnol. 26, 1293-1300 (2008)

81. T. L. Bailey, C. Elkan, Fitting a mixture model by expectation maximization to discover motifs in biopolymers. Proc. Int. Conf. Intell. Syst. Mol. Biol. 2, 28-36 (1994).

82. C. Linhart, Y. Halperin, R. Shamir, Transcription factor and microRNA motif discovery: The Amadeus platform and a compendium of metazoan target sets. Genome Res. 18, 1180-1189 (2008)

83. R. A. Irizary, B. Hobbs, F. Collin, Y. D. Beazer-Barclay, K. J. Antonellis, U. Scherf, T. P. Speed, Exploration, normalization, and summaries of high density oligonucleotide array probe level data. Biostatistics 4, 249-264 (2003).

84. M. J. Dunning, M. L. Smith, M. E. Ritchie, S. Tavaré, beadarray: R classes and methods for lllumina bead-based data. Bioinformatics 23, 2183-2184 (2007).

85. R. Sharan, A. Maron-Katz, R. Shamir, CLICK and EXPANDER: A system for clustering and visualizing gene expression data. Bioinformatics 19, 1787-1799 (2003).

86. I. Ulitsky, A. Maron-Katz, S. Shavit, D. Sagir, C. Linhart, R. Elkon, A. Tanay, R. Sharan, Y. Shiloh, R. Shamir, Expander: From expression microarrays to networks and functions. Nat. Protocols 5, 303-322 (2010).

87. W. Huang da, B. T. Sherman, R. A. Lempicki, Systematic and integrative analysis of large gene lists using DAVID bioinformatics resources. Nat. Protocols 4, 44-57 (2009)

88. A. Paz, Z. Brownstein, Y. Ber, S. Bialik, E. David, D. Sagir, I. Ulitsky, R. Elkon, A. Kimchi, K. B. Avraham, Y. Shiloh, R. Shamir, SPIKE: A database of highly curated human signaling pathways. Nucleic Acids Res. 39, D793-D799 (2011).

Acknowledgments: We are indebted to D. Balzereit, E. Dagand, J. Wilde, M. Linser, S. Dökel, C. Vogelgesang, and A. Sabah for excellent technical support and to R. Rozov for assistance in data analysis. This work was carried out in the framework of the TRIREME consortium, and the contribution of the TRIREME member groups to its success is gratefully acknowledged. We thank J. Bartek for suggesting the use of CAL51 cells in this study. Funding: This work was supported by research grants from the European Union Seventh Framework Program (HEALTH-F4-2009-223575 and 262055-European Sequencing and Genotyping Infrastructure), The Dr. Miriam and Sheldon G. Adelson Medical Research Foundation, the Max Planck Society, the I-CORE Program of the Planning and Budgeting Committee and The Israel Science Foundation (Gene Regulation in Complex Human Disease Center, grant no. 41/11), and The Israel Cancer Research Fund. Y.S. is a Research Professor of the Israel Cancer Research Fund. Author contributions: S.R.-E., H.-J.W., A.K., Y.C., V.A., and M.S. performed experiments. H.-J.W., R.E., H.S., A.P., W.N., and R.S. performed computational work. R.E., H.-J.W., H.L., R.S., M.-L.Y., and Y.S. designed experiments and analyzed the data. R.E., H.-J.W., M.-L.Y., and Y.S. wrote the paper. Competing interests: The authors declare that they have no competing interests. Data and materials availability: The sequencing data reported in this paper were deposited in the Sequence Read Archive database under accession number ERP004219.

Submitted 26 December 2013

Accepted

Final Publication 13 May 2014

10.1126/scisignal.2005032

Citation: S. Rashi-Elkeles, H.-J. Warnatz, R. Elkon, A. Kupershtein, Y. Chobod, A. Paz, V. Amstislavskiy, M. Sultan, H. Safer, W. Nietfeld, H. Lehrach, R. Shamir, M.-L. Yaspo, Y. Shiloh, Parallel profiling of the transcriptome, cistrome, and epigenome in the cellular response to ionizing radiation. Sci. Signal. 7, rs3 (2014). 
Science Signaling

MAAAS
Parallel Profiling of the Transcriptome, Cistrome, and Epigenome in the Cellular Response to Ionizing Radiation Sharon Rashi-Elkeles, Hans-Jörg Warnatz, Ran Elkon, Ana Kupershtein, Yuliya Chobod, Arnon Paz, Vyacheslav Amstislavskiy, Marc Sultan, Hershel Safer, Wilfried Nietfeld, Hans Lehrach, Ron Shamir, Marie-Laure Yaspo and Yosef Shiloh (May 13, 2014)

Science Signaling 7 (325), rs3. [doi: 10.1126/scisignal.2005032]

The following resources related to this article are available online at http://stke.sciencemag.org. This information is current as of March 23, 2015.

Article Tools Visit the online version of this article to access the personalization and article tools:

http://stke.sciencemag.org/content/7/325/rs3

\section{Supplemental Materials}

Related Content

Glossary

Permissions
"Supplementary Materials"

http://stke.sciencemag.org/content/suppl/2014/05/09/7.325.rs3.DC1.html

The editors suggest related resources on Science's sites:

http://stke.sciencemag.org/content/sigtrans/3/124/ra44.full.html http://stke.sciencemag.org/content/sigtrans/5/251/ra83.full.html http://stke.sciencemag.org/content/sigtrans/3/151/rs3.full.html http://stke.sciencemag.org/content/sigtrans/4/156/pe2.full.html http://stke.sciencemag.org/content/sigtrans/2/96/pe73.full.html http://stke.sciencemag.org/content/sigtrans/7/341/re5.full.html http://stke.sciencemag.org/content http://stke.sciencemag.org/content http://stke.sciencemag.org/content/sigtrans/8/368/eg3.full.html

This article cites 88 articles, 23 of which you can access for free at: http://stke.sciencemag.org/content/7/325/rs3\#BIBL

Look up definitions for abbreviations and terms found in this article: http://stke.sciencemag.org/cgi/glossarylookup

Obtain information about reproducing this article: http://www.sciencemag.org/about/permissions.dtl

Science Signaling (ISSN 1937-9145) is published weekly, except the last December, by the American Association for the Advancement of Science, 1200 New York Avenue, NW, Washington, DC 20005. Copyright 2015 by the American Association for the Advancement of Science; all rights reserved. 